\title{
Introduction: Foundational Issues in Philosophical Semantics
}

\author{
Carlotta Pavese ${ }^{1} \cdot$ Andrea lacona $^{2}$
}

Published online: 28 October 2020

(c) Springer Nature B.V. 2020

This issue encompasses eight papers that have been presented at the Topoi Conference 2018-Foundational Issues in Philosophical Semantics - which took place in Turin in June 2018 and was organized by the Center for Logic, Language, and Cognition (LLC) at the University of Turin. The issue also includes five more papers that have been invited or obtained through a call. The papers are topically divided into three main sections that reflect quite closely the original structure of the conference: Choice of paradigm, Core topics in philosophical semantics, and Pragmatics and Communication.

\section{Section I: Choice of Paradigm}

The five papers in this section discuss different foundational frameworks in the theory of meaning. In "Fostering Liars", Pietroski argues that two classical problems for a Davidsonian theory of meaning are fatal for it, when combined. Davidson conjectured that suitably formulated Tarski-style theories of truth can "do duty" as theories of meaning for the spoken languages that humans naturally acquire. But this conjecture faces at least two old objections: Foster's problem and the Liar Paradox. Foster noted that given a theory of the sort Davidson envisioned, for a language L, there will be many equally true theories whose theorems pair endlessly many sentences of $L$ with very different specifications of whether or not those sentences are true. And if L includes the word 'true', then for reasons stressed by Tarski, it is hard to see how any truth theory for L could be correct. Pietroski

Andrea Iacona

andrea.iacona@unito.it

Carlotta Pavese

cp645@cornell.edu

1 Sage School of Philosophy, Cornell University, 218 Goldwin Smith Hall, Ithaca, NY 14853, USA

2 Department of Philosophy and Education, Center for Logic, Language, and Cognition, University of Turin, Via S. Ottavio 20, 10124 Torino, Italy mounts a sustained argument that appealing to possible worlds will not help with Foster's Problem, for reasons that Chomsky $(1957,1977,1995)$ discussed in the 1950s, and appealing to trivalent models of truth will not avoid concerns illustrated with Liar Sentences.

In "Behavioral Foundations for Expression Meaning," Megan Stotts proposes an alternative to a well-established tradition in the philosophy of language, according to which we can understand what makes an arbitrary sound, gesture, or marking into a meaningful linguistic expression only by appealing to mental states, such as beliefs and intentions. Stotts explores the possibility of understanding the meaningfulness of linguistic expressions just in terms of observable linguistic behavior. Specifically, the view explored is one on which a type of sound (or other item) becomes a meaningful linguistic expression within a group in virtue of the production of that type of item becoming that group's widespread, copied way of getting others to involve an object or relation in their activity. After discussing a preliminary version of the view, Stotts defends it against some key concerns about whether it really does eschew mental states, and about its adequacy as an account of linguistic meaning.

In "Truth conditional cognitivism and the lexical problem", Fabrizio Calzavarini discusses a foundational problem for truth-conditional cognitivism - the view that truth-conditional formal semantics for natural language is a theory of semantic competence. Calzavarini rehearses the concern that a number of other authors have expressed according to which truth-conditional formal semantics is unable to provide a complete account of lexical competence, and, therefore, it suffers from incompleteness. The problem is a consequence of Kripke's and Putnam's arguments against the view that semantic values (intension, reference) of words are cognitively determined. According to Calzavarini, these arguments undermine the idea that formal semantics can be, at the same time, a theory of truth-conditions and a theory of semantic competence.

In "Proof-Theoretic Semantics for Natural Language", Nissim Francez introduces us to a proof-theoretical framework for the semantics for natural language. On this 
framework, the meaning of a linguistic expression can be fully specified in terms of its introduction and elimination rules. The first part of the article presents a brief exposition of proof-theoretic semantics, not necessarily in connection to natural language. The second part reviews some of the applications of proof-theoretic semantics to natural languages with an indication of some advantages of this approach over the model-theoretic approach.

In "Mistakes about meaning and conventions," Cosmo Grant advances a novel problem for the view according to which meanings are transparent to speakers. This view takes speakers' judgements about the meanings of sentences of their languages to be, other things being equal, accurate. As Grant points out, this view is rather standard and underlies the Elicitation Method-a typical method in semantic fieldwork, according to which we should work out the truth-conditions of a sentence by eliciting speakers' judgments about its truth-value in different situations. Grant aims to put pressure on this rather standard view and, therefore, on the Elicitation Method. Lewis (1969) gave a theory of convention in a game-theoretic framework that shows how conventions can arise from repeated coordination games, and, as a special case, how meanings could arise from repeated signaling games. In order to show that meanings are in some cases not transparent to their speaker, Grant constructs coordination games in which the players can be wrong about their conventions, and signaling games in which the players can be wrong about their messages' meanings. As Grant shows, knowing your own strategy and payoff need not determine what the others do, so it leaves room for false beliefs about the convention and meanings. Therefore, perhaps the most prominent theory of how conventions and meaning arise is demonstrably in tension with a view on which messages' meanings are transparent.

\section{Section II: Core Topics in Philosophical Semantics}

The four articles collected in this section address four core issues in the philosophy of language: conditionals, Frege's puzzle, presuppositions, and generic sentences. Each of these issues poses serious challenges to any systematic account of natural language semantics, and has deep theoretical implications.

In "Definable Conditionals," Eric Raidl deals with the logic of conditionals. More specifically, it considers the classical analysis due to Stalnaker and Lewis, which is based on a modal reading of the Ramsey Test, and some alternative accounts that have been discussed in the last few years. Raidl shows how these accounts, just as many others, can be treated as definitional variants of one and the same basic account, and develops a formal technique for specifying the logic for each defined conditional by considering them as strengthening or weakening of the basic conditional. Since we have a sound and complete axiom system for the basic conditional, by means of this technique we can prove derived soundness and completeness results for each defined conditional.

In "Transparent Coreference," Francois Recanati outlines and defends an original perspective on the distinction between transparent and non-transparent coreference, which is crucial to the classical problem of identity statements raised by Frege. Recanati explains non-transparent coreference in terms of distinct coreferential files being associated with two token singular terms. The subject may not know that the two files corefer, and thus ascribe contradictory properties to the same object. On the other hand, he argues that, when the same mental file is deployed twice, the subject is bound to know that there is coreference. In such cases, coreference is achieved at the level of referential content, but in addition there is a matching relation holding at the level of cognitive content between constituents of the mental representation.

In "Who's sitting in that chair? Multiple failing presuppositions and truth-value judgments," Martina Rosola examines a debated account of presuppositions due to von Fintel and raises a problem in connection with it. The problem concerns multiple failing presuppositions, a phenomenon illustrated by sentences which contain more than one empty definite description, such as "The person sitting in that chair is the king of France." As her discussion of von Fintel's account and its variants show, the case of multiple failing presuppositions deserves careful attention, and can be adopted as a test for any theory of presupposition. At the end of the article, Rosola explains how von Fintel's proposal could be revised in order to handle the examples considered.

In "A Causal Power Semantics for Generics sentences," Robert Van Roij articulates an analysis of generic sentences in terms of causal powers. More specifically, he investigates the possibility that a sentence of the form 'As are Bs', such as 'Tigers are striped' or 'Wolves attack people', is true because there is a causal connection between the property A and the property B. The initial plausibility of this claim is due to the fact that many generic sentences express inductive generalizations, which typically hold in virtue of causal connections. The article compares the causal analysis with the probabilistic analysis according to which 'As are Bs' is true when relatively many As have feature $\mathrm{B}$, and considers some problems that arise in connection with it.

\section{Section III: Pragmatics \& Communication}

The last section mainly focuses on pragmatics and language use. The four articles it contains can be divided into two groups. Abreu Zalaveta and Mena address general issues 
concerning assertion and communication, while Bianchi and Caponetto discuss the phenomena of illocutionary disablement and silencing.

In "Communication and Variance," Martin Abreu Zavaleta questions the widely accepted view according to which successful communication through assertoric utterances depends on the fact that speakers normally have the same beliefs about the truth-conditions of the sentences they utter. Against this view, Abreu Zavaleta argues that the participants in a conversation often differ as far as those beliefs are concerned. More precisely, nearly every utterance is such that there is no proposition which more than one language user believes to be the truth-conditional content of the utterance. The article develops an alternative picture of communication, and suggests that successful communicative exchanges can be explained in terms of conditions that do not entail sameness of beliefs about truth-conditional content.

In "The Bridge Principle and Stigmatized Truth-Values", Ricardo Mena highlights some difficulties for a standard Stalnakerian theory of pragmatic presuppositions. According to this theory, an utterance $u$ pragmatically presupposes a proposition $q$ if and only if $u$ cannot be felicitous relative to a conversation in which $q$ is not taken for granted. This theory of pragmatic presuppositions encompasses a principle of rational communication - the Bridge Principle - that links pragmatic and semantic presuppositions. According to this principle, an utterance of a sentence cannot be felicitous unless the semantic presuppositions of that sentence are taken for granted by the participants of the conversation. Mena argues that this principle cannot be true as formulated by Stalnaker. If it were, a good number of sentences containing vague predicates would be infelicitous, whereas they are not. In light of this problem, Mena offers an alternative formulation of the Bridge Principle, which is intended to take vagueness into account.

In "Discursive Injustice: The Role of Uptake," Claudia Bianchi aims to develop a theory of discursive injustice that is more plausible and more effective for a critique of the structures of power and oppression. The phenomena of "conversational asymmetry" have become a lively object of study for linguists, philosophers of language, and moral philosophers - under various labels: illocutionary disablement and silencing, discursive injustice, and illocutionary distortion. The common idea is that members of underprivileged groups sometimes have trouble performing particular speech acts that they are entitled to perform: in certain contexts, their performative potential is somehow undermined, and their capacity to do things with words is distorted or even annulled. In this article, Bianchi assesses this idea, focusing on Rebecca Kukla's and Rae Langton's accounts. Bianchi criticizes the role the notion of uptake plays in these accounts, and makes the case that this notion of uptake may ultimately undermine the very idea of discursive injustice. While according to Kukla and Langton, members of disadvantaged groups are victims of a kind of uptake failure, leading to illocutionary disablement and even silencing, on the account Bianchi defends they are better understood as victims of a kind of communicative (neither illocutionary nor perlocutionary) disablement.

In "A Comprehensive Definition of Illocutionary Silencing," Laura Caponetto also discusses the mechanism of illocutionary silencing. Moving beyond the traditional conception of silencing as uptake failure, McGowan (2009, 2014, 2019) has claimed that silencing also involves other forms of recognition failure. Caponetto first offers a supportive elaboration of McGowan's claims by developing a social account of speech act performance, according to which the success of an illocutionary act is not only a function of the intentions of and the conventions deployed by the speaker but partly depends on how the act is recognized or taken up by the hearer. Then Caponetto provides a comprehensive definition of illocutionary silencing and spells out what it means for it to occur in a systematic manner.

\section{References}

Chomsky N (1957) Syntactic structures. Mouton, The Hague Chomsky N (1977) Essays on form and interpretation. North Holland, New York

Chomsky N (1995) Language and nature. Mind 104:1-61

Lewis D (1969) Convention. Cambridge, Mass Harvard UP

McGowan MK (2009) On silencing and sexual refusal. J Politi Philos 17(4):487-494

McGowan MK (2014) Sincerity silencing. Hypatia 29(2):458-473

McGowan MK (2019) Just words: on speech and hidden harm. Oxford University Press, New York

Publisher's Note Springer Nature remains neutral with regard to jurisdictional claims in published maps and institutional affiliations. 